\title{
Do various personal hygiene habits protect us against influenza-like illness?
}

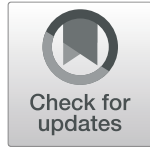

\author{
Amro K. Bin Abdulrahman * (D), Khalid A. Bin Abdulrahman, Mansour K. Almadi, Abdulrahman M. Alharbi, \\ Mahmoud A. Mahmoud, Mohammed S. Almasri, Tariq R. Alanazi, Rakan A. Alarifi, Abdullah A. Kilani, \\ Omar S. Albluwi, Muaath A. Al Fraih, Yaser T. Al Otabi, Hani O. Alanazi, Waleed A. Almufarih, \\ Abdullah M. Alokayli and Omar A. Alwhibi
}

\begin{abstract}
Background: Several studies have reported an association between improvements in hand hygiene and the reductions in rates of intestinal parasitic diseases. However, only a some have addressed its link to the frequency of influenza-like illness. The current study aimed to find the correlation between personal hygiene habits and the frequency of influenzalike illness.

Methods: A cross-sectional study targeting 3000 participants conducted in Riyadh city, Saudi Arabia. A systematic random sampling methodology was applied for participant from different part of Riyadh city using a computer generating system. The researcher first started by calling each participant. A full explanation was given to each participant in details (from the purpose of the research, consent to answer the questionnaire, to the explanation of the outcome definition). Each point of the questionnaire was explained to them to make sure they had excellent comprehension, and therefore, respond accurately. Descriptive statistics and Odds Ratio and its 95\% confidence intervals were used to determine the association between frequency of influenza-like illness and the studied variables.

Results: Two thousand eighty-two (69.4\%) completed the questionnaire. The participants who spent 5-10 s in handwashing with soap and rubbing were at increased risk of more frequent influenza-like illness (odds ratio $=1.37$, 1.08-1.75). Handwashing with soap and rubbing after handshaking is an independent protective habit against frequent influenza-like illness (adjusted OR = 0.59, 0.37-0.94).

Conclusion: The decrease of the frequency of influenza-like illness could be done through the following: getting the influenza vaccine annually, washing hands with soap and hand rubbing not less than $15 \mathrm{~s}$ after getting out of the bathroom, before and after handshaking and before eating. Soap companies should invent soaps that take less rubbing time to kill bacteria, and subsequently may maximize compliance in the community.
\end{abstract}

Keywords: Public health, Personal hygiene, Influenza vaccine, Influenza-like illness, Saudi Arabia

\section{Background}

It is thought that good hygiene habits, such as avoiding the use of other people's personal items may help in the reduction of communicable diseases. Handwashing compliance is a recognized tool in terms of quality and care in various countries around the world [1]. Still, the infection rate is high in many parts of the world, even though hygiene education and health resources are available, so the problem arises from personal practice and behavior

\footnotetext{
* Correspondence: draka.1416@gmail.com

Department of Public Health, College of Medicine, Imam Mohammad Ibn Saud Islamic University, Riyadh, Saudi Arabia
}

in the community. Hand hygiene also plays a role in minimizing acute respiratory infections [2].

The majority of influenza-like illness (ILI) is caused by many different agents that are not clinically distinguishable from one another. A variable proportion of ILI (7 to $15 \%$ on average) is caused by influenza viruses and is known as influenza $[3,4]$.

Seasonal influenza has been estimated to cause 90 million new acute respiratory infection cases worldwide among young children in 2008, [5] and 19,244 disabilityadjusted life years lost across all age groups [6,7].

(c) The Author(s). 2019 Open Access This article is distributed under the terms of the Creative Commons Attribution 4.0 International License (http://creativecommons.org/licenses/by/4.0/), which permits unrestricted use, distribution, and 
Vaccination against influenza is the primary way to reduce the substantial health burden that seasonal influenza causes, and is the primary tool to prevent influenza infection [8].

A study during the H1N1 epidemic assessed the knowledge and attitudes of the Saudi public reported that $38.3 \%$ of participants were not convinced about the truth of published reports about this illness [9]. Of those participants, $16.1 \%$ reported receiving information from health providers about influenza-related guidelines. Another study during the same epidemic confirmed the need for prevention strategies, including immunization and improved personal hygiene in the Saudi population [10].

The hygiene habits of young people's may be motivated by perceptions of socially acceptable behavior rather than by scientific knowledge [11]. Diseases intervention studies suggest that the risk of infectious intestinal disease can be reduced by up to $31 \%$ through hand hygiene [12]. Several studies have reported an association between improvements in hand hygiene and reductions in rates of intestinal parasitic diseases [12-17]. However, only some have addressed the link between personal hygiene, influenza vaccine, and the frequency of influenza-like illness. The current study aims to find the association between personal hygiene habits and the frequency of influenza-like illness.

\section{Methods}

\section{Study design}

A cross-sectional study was undertaken in Riyadh city, the capital of Saudi Arabia.

\section{Study population and sampling}

Three thousand male and female youths and young adults aged from 16 to 45 years were selected. The authors were able to acquire their contact information through the official government Saudi Telecom database, which was clearly explained to them that the communication with them was purely for scientific purposes, and all data of their identities will remain confidential. A systematic random sampling of those randomly selected participant from different parts in Riyadh was applied using a computer generating system to make sure it is representative to the whole city.

\section{Study questionnaire}

The researcher first started by calling each participant. A full explanation was given to each participant in details (from the purpose of the research, consent to answer the questionnaire, to the explanation of the outcome definition). Each point of the questionnaire was explained to them to make sure they had excellent comprehension, and therefore, respond accurately. Survey Monkey program was used as it had easier presentation of the questions to the participant [18]. Next, the participants were asked to answer the questionnaire, which was designed to explore the participant's personal hygiene habits, gender, age, social status, and level of education. The study questionnaire contained 20 questions regarding habits of personal hygiene and related information and four demographic questions. The participants were asked questions that were considered the study variables, which were as follows: hand hygiene habits, use of other personal items, the action is done when sneezing, influenza vaccination and the number of times they had influenzalike illness, in which all of these were asked to be answered from the participant's past 4 weeks to minimize possible recall bias. The questionnaire was subjected to a pilot study by 36 youth and young adult volunteers. Further improvement and rephrasing were carried out accordingly. The influenza vaccination was considered a secondary investigation of the current research.

\section{Exposure definitions}

Different questions were asked. For example, in the past 4 weeks, do you wash your hands before eating? Always, sometimes, rarely, never. On your ordinary day, approximately how much time do you spend washing your hands? Less than $5 \mathrm{~s}, 5-10 \mathrm{~s}, 10-20 \mathrm{~s}, 20-30 \mathrm{~s}$, More than $30 \mathrm{~s}$. Do you wash your hands after handshaking? Always, sometimes, rarely, never. Do you wash your hands before handshaking? Do you wash your hands after getting back home? Do you wash your hands after getting out of the washroom (W.C)?

Do you use other people's personal items? I use other people's towels always, sometimes, rarely, never. I use other people's used spoon. I share smoking shisha (habli babli) with others. I share the drinking straw with others. I share the same used drinking glass with others. I used to touch my eyes and nose? How many times do you get influenza-like illness in 1 year? 1-3 times/ year, 4-6 times / year, 7-10 times / year, more than 10 times / year. What do you do when you are about to sneeze? I sneeze on my hands; I sneeze on my clothes, I sneeze using napkins, I sneeze on my forearm, I sneeze on the air (empty space). Did you take the Influenza vaccine this year? Yes, no. If the answer yes in the previous question, do you take the Influenza vaccine every year? Yes, no.

\section{Outcome definition}

The term influenza-like illness was defined based on the case definition of the World Health Organization, which is an acute respiratory infection with a measured fever of $\geq 38 \mathrm{C}^{\circ}$ and cough; with onset within the last 10 days [19]. 


\section{Data analysis}

The statistical package for social science version 17.0 (SPSS Inc. Chicago, IL) was used to analyze the collected data. Descriptive statistics and Odds Ratio and its 95\% confidence intervals were used to determine the association between the frequency of influenza-like illness and the studied variables. Significant associations in the crude analysis were submitted into the multivariate logistic regression model, and the Odds Ratio was reported.

\section{Results}

Out of 3000, Saudi youth and young adults' participants, $2082(69.4 \%)$ completed the questionnaire. Table 1 showed that the majority were single $(53.2 \%)$ and (46.8\%) were married. Males were (59.8\%), and the majority were at the university level (73.1\%). However, the least percentage was among those who completed only elementary or intermediate levels $(0.6$ and $2.6 \%)$ respectively. The majority were aged $21-30$ years $(48.5 \%)$. The least number of the sample was aged 16-20 (14.5\%).

Table 2 showed the duration of handwashing with soap and rubbing, which were statistically significant in terms of the time spent on handwashing as it showed that the participant who spent 5-10s of handwashing with soap and hand rubbing got influenza-like illness more frequently in comparison to those who washed their hands for long periods. Also, handwashing with soap and hand rubbing behavior was protective against influenza-like illness at all levels (rare, sometimes or always) in the

Table 1 Socio-demographic characteristics of adults regarding their personal hygiene behavior in Saudi Arabia

\begin{tabular}{lll}
\hline Characteristic & $\begin{array}{l}\text { Number } \\
\mathrm{n} \mathrm{2082}\end{array}$ & Percentage (\%) \\
\hline Age $^{\text {a }}$ & 300 & 14.5 \\
$16-20$ & 1005 & 48.5 \\
$21-30$ & 777 & 37 \\
$>30$ & & \\
Gender & 1246 & 59.8 \\
Male & 836 & 40.2 \\
Female & & \\
Marital status & 1108 & 53.2 \\
Single & 974 & 46.8 \\
Married & & \\
Education & 12 & 0.6 \\
Elementary & 55 & 2.6 \\
Intermediate & 493 & 23.7 \\
Secondary & 1522 & 73.1 \\
University &
\end{tabular}

Data are presented as numbers and percentages from the total sample ${ }^{\mathrm{a}} \mathrm{Age}$ is in years following situations: before eating, after using the bathroom and after coming back home.

Statistically significant data showed that handwashing with soap and hand rubbing before and after shaking hands were also protective (Odds ratio $(95 \% \mathrm{CI})=0.62$ (0.46-0.83), $0.32(0.16-0.61)$ respectively.

Table 3 showed the usage of other people's personal items with the frequency of influenza-like illness. It was found that most participants who reported using other people's personal items all the time (e.g., towel, straw, glass, Habli Babli) had an increase in the frequency of getting influenza-like illness in percentages and odds ratio. However, it was not statistically significant.

Table 4 showed a group of miscellaneous behaviors and precautions that people may do or take with the frequency of influenza-like illness. It was found that touching eyes and nose did not affect the risk of the frequency of influenza-like illness (Odds ratio $(95 \% \mathrm{CI})=0.99$ (0.76-1.3), $1.04(0.75-1.44), 1.47(1.0-2.15)$ for rarely, sometimes and always respectively). There were no statistically significant data regarding the action done when sneezing in relation to the frequency of getting influenza-like illness for covering your nose with hands, clothes, napkins or forearm, $($ Odds ratio $(95 \% \mathrm{CI}))=1.06$ (0.8-1.4), 1.18 (0.77-1.81), 1.30 (0.98-1.73), 1.03 (0.711.49) respectively.

Moreover, participants who reported taking the annual vaccination against influenza showed more protection against frequent influenza-like illness (Odds ratio $(95 \%$ $\mathrm{CI})=0.47(0.25-0.90)$.

Table 5 represents the multivariate logistic regression analysis, which showed that the annual vaccination against influenza was independently protective against frequent influenza-like illness (adjusted OR $=0.49(0.25$ 0.96). Also, handwashing with soap and rubbing after handshaking was an independent protective habit against frequent influenza-like illness (adjusted odds ratio (95\% CI) $=0.59(0.37-0.94)$.

\section{Discussion}

To our knowledge, this is the first study conducted in Saudi Arabia that brings which have found a correlation between a variety of personal hygiene habits and influenza vaccine with the frequency of influenza-like illness.

This study found that handwashing with soap and rubbing was protective against influenza-like illness. Several studies were consistent with our findings [2, 20-27].

Participants spending 5-10s in handwashing with soap and rubbing were at increased risk of more frequent influenza-like illness. Also, it turned out that handwashing with soap and rubbing before eating, after using the bathroom and after coming back home was protective from influenza-like illness regardless of the frequency. Interestingly Pires et al. have found that the 
Table 2 Handwashing with soap and rubbing and frequency of having influenza-like illness among adults in Saudi Arabia

\begin{tabular}{|c|c|c|c|c|}
\hline \multirow[t]{2}{*}{ Habit } & \multicolumn{2}{|c|}{$\begin{array}{l}\text { Frequency of influenza-like illness in the past } 4 \text { weeks } \\
\text { n } 2082(\%)\end{array}$} & \multirow[t]{2}{*}{ OR } & \multirow[t]{2}{*}{$\begin{array}{l}95 \% \text { Conf. } \\
\text { Interval }\end{array}$} \\
\hline & $1-3^{b}$ & $>3^{b}$ & & \\
\hline \multicolumn{5}{|c|}{ Duration of hand washing } \\
\hline$<5 s$ & $144(28.1)$ & $356(22.7)$ & REF & \\
\hline $5-10 s$ & $246(47.3)$ & $822(52.4)$ & 1.37 & $1.08-1.75^{\mathrm{a}}$ \\
\hline $10-20 s$ & $85(16.6)$ & $265(16.9)$ & 1.26 & $0.92-1.72$ \\
\hline $20-30 s$ & $24(4.7)$ & $77(4.9)$ & 1.3 & $0.79-2.13$ \\
\hline$>30 s$ & $17(3.3)$ & $50(3.2)$ & 1.19 & $0.66-2.13$ \\
\hline \multicolumn{5}{|c|}{ Hand washing before eating } \\
\hline Never & $270(52.7)$ & $965(61.5)$ & REF & \\
\hline Rarely & $195(38.1)$ & $530(33.8)$ & 0.28 & $0.23-0.34^{a}$ \\
\hline Sometimes & $37(7.2)$ & $65(4.1)$ & 0.49 & $0.32-0.75^{a}$ \\
\hline Always & $10(2.0)$ & $10(0.6)$ & 0.28 & $0.12-0.68^{a}$ \\
\hline \multicolumn{5}{|c|}{ Hand washing after using the bathroom } \\
\hline Never & $386(75.4)$ & $1354(86.2)$ & REF & \\
\hline Rarely & $101(19.7)$ & $184(11.7)$ & 0.52 & $0.4-0.68^{\mathrm{a}}$ \\
\hline Sometimes & $16(3.1)$ & $22(1.4)$ & 0.39 & $0.2-0.75^{\mathrm{a}}$ \\
\hline Always & $9(1.8)$ & $10(0.6)$ & 0.31 & $0.13-0.78^{a}$ \\
\hline \multicolumn{5}{|c|}{ Hand washing after coming back home } \\
\hline Never & $131(25.6)$ & $481(30.6)$ & REF & \\
\hline Rarely & $165(32.2)$ & $489(31.1)$ & 0.81 & $0.62-1.05$ \\
\hline Sometimes & $86(16.8)$ & $266(16.9)$ & 0.84 & $0.62-1.15$ \\
\hline Always & $130(25.4)$ & $334(21.3)$ & 0.70 & $0.53-0.93^{a}$ \\
\hline \multicolumn{5}{|c|}{ Hand washing after handshaking } \\
\hline Never & $11(2.1)$ & $51(3.2)$ & REF & \\
\hline Rarely & $100(19.5)$ & $383(24.4)$ & 0.8 & $0.4-1.6$ \\
\hline Sometimes & $160(31.3)$ & $388(24.7)$ & 0.5 & $0.26-1.03$ \\
\hline Always & $241(47.1)$ & $748(47.6)$ & 0.32 & $0.16-0.61^{a}$ \\
\hline \multicolumn{5}{|c|}{ Hand washing before handshaking } \\
\hline Never & $146(28.5)$ & $554(35.3)$ & REF & \\
\hline Rarely & $135(26.4)$ & $399(25.4)$ & 0.77 & $0.6-1.01$ \\
\hline Sometimes & $101(19.7)$ & $238(15.2)$ & 0.62 & $0.46-0.83^{a}$ \\
\hline Always & $130(25.4)$ & $379(24.1)$ & 0.76 & $0.59-1.00$ \\
\hline
\end{tabular}

OR Odds Ratio

The data are presented as numbers (\%) and 95\%Confidence Interval for comparison and Statistical significance

${ }^{\text {a }}$ Statistically significant difference

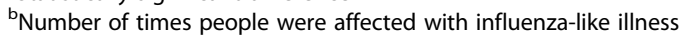

time needed to kill bacteria, a person should rub for at least 15-30 s [28]. So, this makes the duration of handwashing itself a crucial factor in prevention. Most people's underestimate the value of washing hands to maintain clean hands regularly [29].

Furthermore, washing hands with soap and rubbing before and after shaking hands were also protective against having an influenza-like illness. This finding emphasizes the importance of washing hands before and after any action - what we would call good hygiene habits.

Although Aiello et al. have found in their metaanalysis study that hand washing alone was not enough for efficacy against laboratory-confirmed influenza. However, the total percentage of respiratory diseases prevented by hand-hygiene interventions was 21\% (95\% $\mathrm{CI}=5,34 \%$ ). Moreover, hand-washing education done by non-antibacterial soap was a. 
Table 3 Usage of other people's personal items and the frequency of influenza-like illness adults in Saudi Arabia

\begin{tabular}{|c|c|c|c|c|}
\hline \multirow[t]{2}{*}{$\begin{array}{l}\text { Personal } \\
\text { Belongings }\end{array}$} & \multicolumn{2}{|c|}{$\begin{array}{l}\text { Frequency of influenza-like illness in the past } 4 \text { weeks } \\
\text { n } 2082(\%)\end{array}$} & \multirow[t]{2}{*}{ OR } & \multirow{2}{*}{$\begin{array}{l}95 \% \\
\text { Conf. } \\
\text { Interval }\end{array}$} \\
\hline & $1-3^{* *}$ & $>3^{* *}$ & & \\
\hline \multicolumn{5}{|c|}{ Other people's towel } \\
\hline Never & $11(5.6)$ & $26(5.2)$ & REF & \\
\hline Rarely & $42(21.5)$ & $91(18.3)$ & 0.92 & $0.41-2.03$ \\
\hline Sometimes & $33(16.9)$ & $91(18.3)$ & 1.17 & $0.52-2.62$ \\
\hline Always & $109(55.9)$ & $288(58.1)$ & 1.21 & $0.53-2.34$ \\
\hline \multicolumn{5}{|c|}{ Other people's spoon } \\
\hline Never & $11(5.6)$ & $29(5.8)$ & REF & \\
\hline Rarely & $34(17.3)$ & $97(19.4)$ & 0.92 & $0.42-2.05$ \\
\hline Sometimes & $38(19.3)$ & 93 (18.6) & 0.86 & $0.50-1.48$ \\
\hline Always & $114(57.9)$ & $281(56.2)$ & 0.86 & $0.55-1.35$ \\
\hline \multicolumn{5}{|c|}{ Other people's Habli Babli (shisha) } \\
\hline Never & $17(8.9)$ & $33(6.7)$ & REF & \\
\hline Rarely & $25(13.0)$ & $49(9.9)$ & 1 & $0.47-2.15$ \\
\hline Sometimes & $16(8.3)$ & $25(5.0)$ & 0.8 & $0.34-1.9$ \\
\hline Always & $134(69.8)$ & $389(78.4)$ & 1.5 & $0.81-2.77$ \\
\hline \multicolumn{5}{|c|}{ Other people's straw } \\
\hline Never & $3(1.6)$ & $7(1.4)$ & REF & \\
\hline Rarely & $25(13.0)$ & $70(14.1)$ & 1.2 & $0.28-5.0$ \\
\hline Sometimes & $33(17.1)$ & $56(11.3)$ & 0.73 & $0.18-3.0$ \\
\hline Always & $132(68.4)$ & $364(73.2)$ & 1.18 & $0.3-4.6$ \\
\hline \multicolumn{5}{|c|}{ Other people's used glass } \\
\hline Never & $33(16.5)$ & 59 (11.6) & REF & \\
\hline Rarely & $64(32.0)$ & $176(34.6)$ & 1.54 & $0.92-2.57$ \\
\hline Sometimes & $44(22.0)$ & $108(21.2)$ & 1.37 & $0.79-2.38$ \\
\hline Always & $59(29.5)$ & 166 (32.6) & 1.57 & $0.94-2.65$ \\
\hline
\end{tabular}

OR Odds Ratio

The data are presented as numbers (\%) and 95\%Confidence Interval for comparison and Statistical significance

${ }^{* *}$ Number of times people were affected with influenza-like illness

precise preventative measure, as it prevented 51\% $(95 \% \mathrm{CI}=39,60 \%)$ of respiratory diseases in comparison with the controlled group that did not have an intervention [27]. Nevertheless, Wong et al. have found that the overall impact of hand hygiene in protection from influenza was modest [30].

As there were previous statements from experts that using other people's items might affect getting the influenza-like illness. However, the participants who used other people's towel, straw, glass, and habli babli did get affected more frequently with influenza-like illness. Nevertheless, this increase was in the percentage and odds ratio, and it was not statistically significant.

It seemed like repeated touching of eyes and nose, and the action is done when sneezing (e.g., on hands, using napkins) did not affect the frequency of getting the influenza-like illness. Moreover, the annual vaccination against influenza protects against frequent influenza-like illness. There were several studies, which have supported our findings [31-33]. Annual influenza vaccines and handwashing with soap and rubbing after handshaking was independently protective against frequent influenzalike illness.

The current study supported the evidence of the link between handwashing with soap and rubbing and the decrease in the frequency of influenza-like illness. While, washing hands are considered applicable, easy to administer, and cost-effective, healthy habit that does not take a lot of time, yet protects us from many diseases. However, lack of proper hand hygiene is considered a global issue. Unfortunately, our finding leads us to think that people's may tend to wash their hands only if there was visible dirt. Efforts regarding awareness of proper hand hygiene behavior need to be maximized. 
Table 4 Miscellaneous behaviors and influenza vaccine in relation to the frequency of influenza-like illness among adults in Saudi Arabia

\begin{tabular}{|c|c|c|c|c|}
\hline \multirow[t]{2}{*}{ Behavior } & \multicolumn{2}{|c|}{$\begin{array}{l}\text { Frequency of influenza-like illness in } 4 \text { weeks } \\
\text { n } 2082(\%)\end{array}$} & \multirow[t]{2}{*}{ OR } & \multirow[t]{2}{*}{$\begin{array}{l}95 \% \text { Conf. } \\
\text { Interval }\end{array}$} \\
\hline & $1-3^{b}$ & $>3^{b}$ & & \\
\hline \multicolumn{5}{|c|}{ Touch my eyes and nose } \\
\hline Never & $97(18.9)$ & $283(18.0)$ & REF & \\
\hline Rarely & $266(52.0)$ & $771(49.1)$ & 0.99 & $0.76-1.3$ \\
\hline Sometimes & $98(19.1)$ & $298(19.0)$ & 1.04 & $0.75-1.44$ \\
\hline Always & $51(10.0)$ & $218(13.9)$ & 1.47 & $1.0-2.15$ \\
\hline \multicolumn{5}{|l|}{ Action on sneezing } \\
\hline On my hands & $478(30.4)$ & $148(28.9)$ & 1.06 & $0.8-1.4$ \\
\hline On my clothes & $113(7.2)$ & $39(7.6)$ & 1.18 & $0.77-1.81$ \\
\hline Using napkins & $438(27.9)$ & $166(32.4)$ & 1.30 & $0.98-1.73$ \\
\hline On my forearm & $184(11.7)$ & $55(10.7)$ & 1.03 & $0.71-1.49$ \\
\hline On the air & $357(22.7)$ & $104(20.3)$ & REF & \\
\hline \multicolumn{5}{|c|}{ Influenza Vaccination this } \\
\hline \multicolumn{5}{|l|}{ Year } \\
\hline Yes & $106(6.8)$ & $42(8.2)$ & 1.23 & $0.85-1.79$ \\
\hline No & $1464(93.2)$ & $470(91.8)$ & REF & \\
\hline \multicolumn{5}{|c|}{ Annual influenza vaccination } \\
\hline Yes & $66(15.1)$ & $12(7.8)$ & 0.47 & $0.25-0.90^{a}$ \\
\hline No & $370(84.9)$ & $142(92.2)$ & REF & \\
\hline
\end{tabular}

OR Odds Ratio

The data are presented as numbers (\%) and 95\%Confidence Interval for comparison and Statistical significance

${ }^{\text {a }}$ Statistically significant difference

${ }^{\mathrm{b}}$ Number of times people were affected with influenza-like illness

Furthermore, the present study emphasizes the awareness of not just washing hands-on everyday occasions, such as before eating. It is recommended even on other circumstances such as after getting out of the bathroom, after coming back home, and before shaking hands. Although, the finding of this study regarding using shared items with others did not affect the frequency of getting influenza-like illness with statistical significance. However, this does not make it a healthy behavior, and therefore, caution must be taken, unless urgent situations force you to do so.

While there were previous statements regarding behaviors such as frequent touching of eyes and nose and sneezing in a wrong way, such as on hands might affect

Table 5 Independent factors determining the frequency of influenza-like illness among adults in Saudi Arabia

\begin{tabular}{lll}
\hline Factor & Adjusted Odds Ratio & $95 \%$ Conf. Interval. \\
\hline Annual influenza vaccination & 0.49 & $0.25-0.96^{\mathrm{a}}$ \\
Hand washing after shaking & 0.59 & $0.37-0.94^{\mathrm{a}}$
\end{tabular}

The data are presented as 95\% Confidence Interval for comparison and statistical significance

${ }^{\text {a }}$ Statistically significant difference the frequency of influenza-like illness. Hence, these behaviors should not be considered significant points when preparing health promotion activities and materials. Although it is uncommon for a health provider to advise people to wash their hands with soap and to rub after shaking hands. The current study helps health providers and authorities to emphasize its importance. This study support the previous statements of experts in public health, who stated that vaccine could significantly play an essential role in the reduction of frequency of influenza-like illness.

\section{Limitations}

The authors had to make the age group from 16 to 45 years, as in Saudi Arabia, the middle age group of 16-64 makes up the greatest share of the total population (64.8\%). There was a chance of recall bias among the participants. However, the participants were asked to answer the questions based on their behavior in the last 4 weeks, which minimized the recall bias. The duration of hand-washing reported by participants might not have been accurate $100 \%$. However, they were asked to have an approximate estimation, as it is difficult to bring all participants in one place, and observe the time they 
spend washing their hands. Finally, there might have been some participants who did not answer the questionnaire as they should due to un-clear comprehension of the questions. However, this matter has been addressed since the beginning, as each participant was approached individually, and was given a full explanation of each part of the questionnaire.

\section{Conclusion}

This study presents evidence from Saudi Arabia that could contribute to the increase in public health promotion measures. The decrease of the frequency of influenza-like illness could be done through the following: getting the influenza vaccine annually, washing hands with soap and hand rubbing not less than $15 \mathrm{~s}$ after getting out of the bathroom, before and after handshaking and before eating. Moreover, some people don't spend enough time performing proper hand hygiene because they are not used to it. Therefore, soap companies should invent soaps that take less rubbing time to kill bacteria, and subsequently may maximize compliance.

\section{Acknowledgments}

The authors would like to acknowledge Prof. Ashri for his help in data analysis.

\section{Authors' contributions \\ $A B$ substantially contributed to the study design, analysis, and interpretation of data, and drafted the first version and critically revised the final version of the manuscript. KB significantly contributed to the study design and interpretation of data and critically revised the manuscript. MM1 substantially contributed to the study design and critically revised the manuscript. MM2, MM3, TA, RA, AH, AK, OA, MF, YO, HA, WM, AO, OW, have critically revised the manuscript. All authors read and approved the final manuscript.}

\section{Funding}

The authors report no funding.

\section{Availability of data and materials}

The datasets analyzed during the current study is available from the corresponding author on reasonable request. Due to data protection restrictions and participant confidentiality, we do not make participant data publicly available.

\section{Ethics approval and consent to participate}

A written consent was obtained from all participants before data collection. All the selected respondents were given assurance of confidentiality that the information gathered will be used exclusively for research purposes. All participant agreed to participate before answering the questions. The Institutional Review made Board were aware of each step of this research. They made full review and approved the current study of the College of Medicine; Imam Mohammad Ibn Saud Islamic University (IRB number no. 00110/01/2015). IRB registration with KACST, KSA HAPO-01-R-010.

\section{Consent for publication}

Not applicable.

\section{Competing interests}

The authors declare that they have no competing interests.
Received: 12 August 2019 Accepted: 9 October 2019

Published online: 22 October 2019

\section{References}

1. Lin Huang G, Stewardson A, Lindsay Grayson M. Back to basics. Curr Opin Infect Dis. 2014;27(4):379-89.

2. Warren-Gash C, Fragaszy E, Hayward A. Hand hygiene to reduce community transmission of influenza and acute respiratory tract infection: a systematic review. Influenza Other Respir Viruses. 2012;7(5):738-49.

3. Jefferson TO. Mistaken identity: seasonal influenza versus influenza-like illness. Clin Evid. 2009:329:1-4.

4. Demicheli V, Jefferson T, Ferroni E, Rivetti A, Di Pietrantonj C. Vaccines for preventing influenza in healthy adults. Cochrane Database Syst Rev. 2018; 2(2):CD001269. Published 2018 Feb 1. https://doi.org/10.1002/14651858. CD001269.pub6.

5. Ram PK, DiVita MA, Khatun-e-Jannat K, et al. Impact of Intensive Handwashing Promotion on Secondary Household Influenza-Like Illness in Rural Bangladesh: Findings from a Randomized Controlled Trial. PLoS One. 2015;10(6):e0125200. Published 2015 Jun 11. https://doi.org/10.1371/journal. pone. 0125200.

6. Nair H, Brooks WA, Katz M, Roca A, Berkley JA, et al. Global burden of respiratory infections due to seasonal influenza in young children: a systematic review and meta-analysis. Lancet. 2011;378:1917-30. https://doi. org/10.1016/S0140-6736(11)61051-9 [PubMed] [CrossRef] [Google Scholar].

7. Murray CJL, Vos T, Lozano R, Naghavi M, Flaxman AD, et al. Disabilityadjusted life years (DALYs) for 291 diseases and injuries in 21 regions, 19902010: a systematic analysis for the global burden of disease study 2010. Lancet. 2012;380:2197-223. https://doi.org/10.1016/S0140-6736(12)61689-4 [PubMed] [CrossRef] [Google Scholar].

8. Zeitouni MO, Al Barrak AM, Al-Moamary MS, Alharbi NS, Idrees MM, Al Shimemeri AA, et al. The Saudi thoracic society guidelines for influenza vaccinations. Ann Thorac Med. 2015;10:223-30.

9. Balkhy HH, Abolfotouh MA, Al-Hathlool RH, Al-Jumah MA. Awareness, attitudes, and practices related to the swine influenza pandemic among the Saudi public. BMC Infect Dis. 2010;10:42 [PMCID: PMC2844401] [PubMed: 20187976].

10. BinSaeed AA. Characteristics of pandemic influenza A (H1N1) infection in patients presenting to a university hospital in Riyadh, Saudi Arabia. Ann Saudi Med. 2010;30:59 [PMCID: PMC2850183] [PubMed: 20103959].

11. Miko B, Cohen B, Conway L, Gilman A, Seward S, Larson E. Determinants of personal and household hygiene among college students in New York City, 2011. Am J Infect Control. 2012;40(10):940-5.

12. Patrick $D$, Findon $G$, Miller T. Residual moisture determines the level of touch-contact-associated bacterial transfer following hand washing. Epidemiol Infect. 1997:119(3):319-25.

13. Mahmud M, Spigt M, Bezabih A, Pavon I, Dinant G, Velasco R. Efficacy of Handwashing with soap and nail clipping on intestinal parasitic infections in school-aged children: A factorial cluster randomized controlled trial. PLoS Med. 2015;12(6):e1001837.

14. Hosain G, Saha S, Begum A. Impact of sanitation and health education on intestinal parasite infection among primary school-aged children of Sherpur, Bangladesh. Trop Dr. 2003;33(3):139-43.

15. Baker J, Trinies V, Bronzan R, Dorkenoo A, Garn J, Sognikin S, Freeman M. The associations between water and sanitation and hookworm infection using cross-sectional data from Togo's national deworming program. PLoS Negl Trop Dis. 2018;12(3):e0006374.

16. Watson J, Ensink J, Ramos M, Benelli P, Holdsworth E, Dreibelbis R, Cumming $\mathrm{O}$. Does targeting children with hygiene promotion messages work? The effect of handwashing promotion targeted at children, on diarrhea, soil-transmitted helminth infections, and behavior change, in lowand middle-income countries. Tropical Med Int Health. 2017;22(5):526-38.

17. Strunz E, Addiss D, Stocks M, Ogden S, Utzinger J, Freeman M. Water, sanitation, hygiene, and soil-transmitted Helminth infection: A systematic review and meta-analysis. PLoS Med. 2014;11(3):e1001620.

18. SurveyMonkey: The World's Most Popular Survey Tool. (2015). Retrieved from https://www.surveymonkey.com

19. WHO surveillance case definitions for ILI Retrieved from https:/www.who.int/ influenza/surveillance_monitoring/ili_sari_surveillance_case_definition/en/

20. Jefferson T, Del Mar C, Dooley L, Ferroni E, Al-Ansary L, Bawazeer G, et al. Physical interventions to interrupt or reduce the spread of respiratory viruses. Cochrane Database Syst Rev. 2011:CD006207. https://doi.org/10. 1002/14651858.CD006207. 
21. Aiello A, Coulborn R, Perez V, Davis B, Uddin M, Murray G, et al. A randomized intervention trial of mask use and hand hygiene to reduce seasonal influenza-like illness and influenza infections among young adults in a university setting. Int J Infect Dis. 2010;14:e320.

22. Aiello $\mathrm{A}$, Larson $\mathrm{E}$. What is the evidence for a causal link between hygiene and infections? Lancet Infect Dis. 2002;2(2):103-10.

23. Cowling B, Zhou Y, Ip D, Leung GM, Aiello AE. Face masks to prevent transmission of influenza virus: a systematic review. Epidemiol Infect. 2010; 138(04):449.

24. Bloomfield S, Aiello A, Cookson B, O'Boyle C, Larson E. The effectiveness of hand hygiene procedures in reducing the risks of infections in home and community settings, including handwashing and alcohol-based hand sanitizers. Am J Infect Control. 2007;35(10):S27-64.

25. Liu M, Ou J, Zhang L, Shen X, Hong R, Ma H, et al. Protective effect of handwashing and good hygienic habits against seasonal influenza. Medicine. 2016;95(11):e3046.

26. Wu S, Ma C, Yang Z, Yang P, Chu Y, Zhang H, et al. Hygiene behaviors associated with influenza-like illness among adults in Beijing, China: A large, population-based survey. PLoS One. 2016;11(2):e0148448.

27. Aiello A, Coulborn R, Perez V, Larson E. Effect of hand hygiene on infectious disease risk in the community setting: A meta-analysis. Am J Public Health. 2008;98(8):1372-81.

28. Pires D, Soule H, Bellissimo-Rodrigues F, Gayet-Ageron A, Pittet D. Hand hygiene with alcohol-based hand rub: how long is long enough? Infect Control Hosp Epidemiol. 2017;38(05):547-52.

29. Suess T, Remschmidt C, Schink S, Schweiger B, Nitsche A, Schroeder K, et al. The role of facemasks and hand hygiene in the prevention of influenza transmission in households: results from a cluster-randomized trial; Berlin, Germany, 2009-2011. BMC Infect Dis. 2012;12(1):26.

30. Wong V, Cowling B, Aiello A. Hand hygiene and risk of influenza virus infections in the community: a systematic review and meta-analysis. Epidemiol Infect. 2014;142(05):922-32.

31. Jefferson T, Di Pietrantonj C, Rivetti A, Bawazeer G, Al-Ansary L, Ferroni E. Vaccines for preventing influenza in healthy adults. Cochrane Database Syst Rev. 2010;2:CD001269.

32. Rivetti D, Jefferson T, Thomas R, Rudin M, Rivetti A, Di Pietrantonj C, Demicheli V. Vaccines for preventing influenza in the elderly. Cochrane Database Syst Rev. 2006;2:CD004876.

33. Manzoli L, loannidis J, Flacco M, De Vito C, Villari P. Effectiveness and harms of seasonal and pandemic influenza vaccines in children, adults and elderly. Hum Vaccin Immunother. 2012;8(7):851-62.

\section{Publisher's Note}

Springer Nature remains neutral with regard to jurisdictional claims in published maps and institutional affiliations.

Ready to submit your research? Choose BMC and benefit from:

- fast, convenient online submission

- thorough peer review by experienced researchers in your field

- rapid publication on acceptance

- support for research data, including large and complex data types

- gold Open Access which fosters wider collaboration and increased citations

- maximum visibility for your research: over $100 \mathrm{M}$ website views per year

At $\mathrm{BMC}$, research is always in progress.

Learn more biomedcentral.com/submissions 